\title{
Molecular Rigidity/Flexibility Dependence of Mesomorphism
}

\author{
Muniya N. R. ${ }^{\text {a }}$, V. R. Patel* \\ Chemistry Dept.; Sheth P. T. Arts \& Science College, Godhra - 389 001, Gujarat University, \\ Gujarat, India. \\ Email: *: vrp181968@gmail.com \\ a: nikitamuniya26@gmail.com
}

Keywords: Mesophase, Mesogen, Smectic, Nematic, Enantiotropy.

\begin{abstract}
A novel chalconyl homologous series of liquid crystalline derivatives; $\mathrm{RO}-\mathrm{C}_{6} \mathrm{H}_{4}-$ $\mathrm{CH}: \mathrm{CH}-\mathrm{COO}-\mathrm{C}_{6} \mathrm{H}_{4}-\mathrm{CO}-\mathrm{CH}: \mathrm{CH}-\mathrm{C}_{6} \mathrm{H}_{4}-\mathrm{OC}_{8} \mathrm{H}_{17}$ (n) (para) have been synthesized and studied with a view to correlate the thermotropic liquid crystal (LC) behavioural properties and the molecular structure of a substance. Present novel series consisted of eleven homologue members $\left(\mathrm{C}_{1}\right.$ to $\left.\mathrm{C}_{16}\right)$ whose, only nematogenic mesomorphism commences from $\mathrm{C}_{3}$ homologue and continued upto $\mathrm{C}_{16}$ homologue in enantiotropic manner with absence of smectogenic character. Transition temperatures and textures of nematic phase were determined using an optical polarizing microscopy equipped with a heating stage (POM). Transition curve Cr-N/I behaved in normal manner. N-I transition curve exhibited odd-even effect and deviated from its normal descending tendency from and beyond $\mathrm{C}_{8}$ homologue and adopted serpantile shape from $\mathrm{C}_{8}$ to $\mathrm{C}_{16}$ homologue in deviating manner. Textures of the nematic phase are threaded or schlieren. Analytical and spectral data supported molecular structures of homologues. Thermal stability for nematic is 112.66 and the degree of mesomorphism vary from $5.0^{\circ} \mathrm{C}$ to $44.0^{\circ} \mathrm{C}$ at the $\mathrm{C}_{12}$ andC $\mathrm{C}_{4}$ homologue respectively. It is a middle ordered melting type series, whose relative group efficiency order for nematic derived.
\end{abstract}

\section{INTRODUCTION}

Thermotropically liquid crystalline (LC) [1] novel homologues of chalconyl derivatives are important from the point of view of their applicability $[2,3,4,5,6,7]$ in the manufacture of LC devices to be operated at desired or room temperature and their bioactivities to be exploited as anticancer, antimalarial, antibacterial etc in the benefit of mankind. Therefore present investigation was planned to synthesize novel chalconyl ester derivatives which can be useful to all scientific and technological research investigators working on LC state with different aims, objects and views with different angle. The present aim of investigation is fixed with a view to understand and establish the effect of molecular structure $[8,9,10,11,12,13]$ on properties of thermotropic LC substances, which includes even a minor change in molecular structure can bring about major change in LC behaviour as a consequence of changing molecular rigidity and/or flexibility $[14,15,16,17]$. Numbers of chalconyl ester or azoester or simple esters have been reported till the date $[18,19,20,21,22,23,24]$. The synthesis of novel homologues of proposed investigation after their due characterisation will be compared with other structurally similar analogous series and then group efficiency order will be derived with respect to thermal stability, early commencement of mesophase and the degree of mesomorphism.

\section{EXPERIMENTAL}

\section{Synthesis:}

4- Hydroxy benzaldehyde was alkylated by usual established method [25a]. n-alkoxy benzaldehydes were treated with malonic acid to convert them into 4-n-alkoxy cinnamic acids (A) [25b]. n-alkoxy cinnamic acids were condensed with $\alpha-4$ hydroxy benzoyl -4 ' octyloxy phenyl ethelene [26] [B] (m.p. $117^{\circ} \mathrm{C}$ ) by usual established method. Components A and B were condensed 
[27] to give final products. Synthetic route to usual series is mentioned below as scheme-1. Final products were individually decomposed, filtered, washed, dried and purified till the constant transition temperatures obtained.

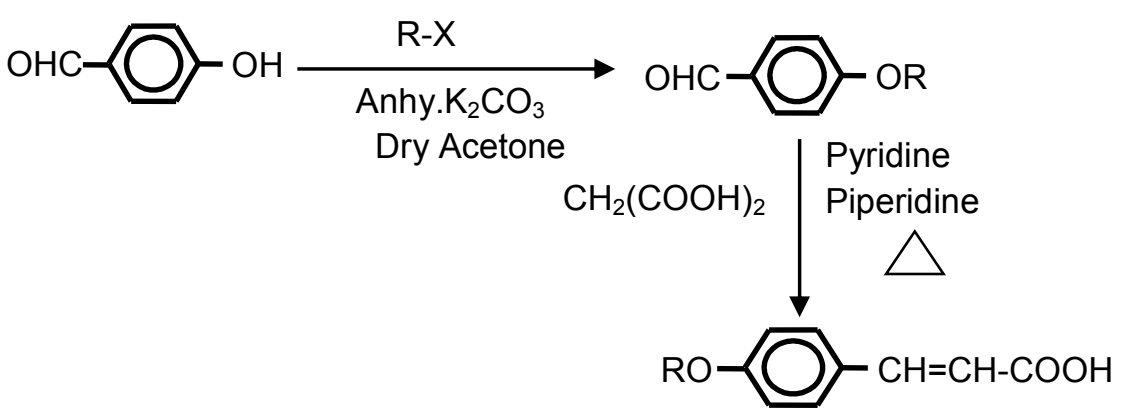

(A)

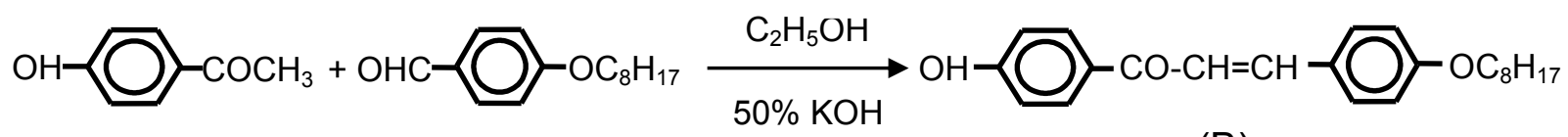

(B)

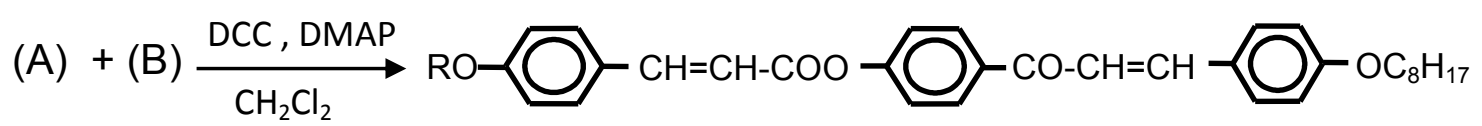

Final product

Where, $\mathrm{R}=\mathrm{C}_{\mathrm{n}} \mathrm{H}_{2 \mathrm{n}+1}, \mathrm{n}=1,2,3,4,5,6,8,10,12,14,16$.

The chemicals 4- hydroxyl benzaldehyde, melonic acid, alkyl halides, 4- hydroxy acetophenone, 4decyloxy benzaldehyde, potassium Hydroxide, hydrochloric acid etc. required for synthesis were used as received except solvents which were dried and distilled prior to synthesis

Scheme-1: Synthetic route to the series-1

\section{Characterization:}

Some selected members of the titled series were characterized by elemental analysis, ${ }^{1} \mathrm{HNMR}$ spectra and IR spectra, Textures of mesophases were characterized by miscibility method. Microanalysis for C,H,N, elements was performed on Perkin Elmer PE 2400 analyzer (Table-1). ${ }^{1} \mathrm{HNMR}$ spectra were obtained on Bruker spectrometer using $\mathrm{CDCl}_{3}$ as solvent. IR spectra were recorded on a Perkin- Elmer spectrum GX. Transition temperatures and liquid crystal properties were investigated using an optical polarizing microscope equipped with a heating stage.

Table-1: Elemental analysis for the decyloxy, dodecyloxy and tetradecyloky derivatives

\begin{tabular}{|c|c|c|}
\hline & \multicolumn{2}{|c|}{ Elemental \% found (Compared with \% calculated) } \\
\hline Molecular formula & C & H \\
\hline $\mathrm{C}_{42} \mathrm{H}_{54} \mathrm{O}_{5}$ & $78.95(79.00)$ & $8.25(8.46)$ \\
\hline $\mathrm{C}_{44} \mathrm{H}_{58} \mathrm{O}_{5}$ & $78.10(79.28)$ & $8.66(8.71)$ \\
\hline $\mathrm{C}_{46} \mathrm{H}_{62} \mathrm{O}_{5}$ & $79.01(79.54)$ & $8.54(8.93)$ \\
\hline
\end{tabular}




\section{ANALYTICAL DATA}

$\mathbf{H}^{1}$ NMR: in ppm. For Octyloxy homologue.

Ethylenes: (200 MHZ) $\delta\left(\mathrm{CDCl}_{3}\right)(\mathrm{ppm}) 0.85\left(-\mathrm{CH}_{3}-\mathrm{CH}_{2}\right.$ of $\left.-\mathrm{C}_{8} \mathrm{H}_{17}\right), 1.25$ (long- $\mathrm{CH}_{2}$ - chain), $3.5-\mathrm{OCH}_{2}$ of $\left(-\mathrm{OCH}_{2}\right.$ of $\left.\mathrm{C} 8 \mathrm{H}_{17}\right), 4.44$ and $4.02-\mathrm{CH}=\mathrm{CH}, 6.89 \& 6.92$,(p-sub. benzene rings) 7.80 $\& 8.02$ (two p-sub. benzene rings)

H$^{1}$ NMR: in ppm. For Decyloxy homologue.

Ethylenes: (200 MHZ) $\delta(\mathrm{CDCl} 3)(\mathrm{ppm}) 1.20-\mathrm{CH} 3,3.95-\mathrm{O} \mathrm{CH} 2,4.01-\mathrm{O} \mathrm{CH} 2$ of OCH2-CH2-CH3, 4.40 and $4.02-\mathrm{CH}-\mathrm{CH}, 6.89,6.92,8.00$, and 8.03 -p-sub.phenyl, two psub.benzene, 7.24 and 8.02 - p-subphenyl two p-subbenzene,

IR in $\mathbf{C m}^{-1}$, For Octyloxy homologue.

Ethylenes: (vmax/cm-1): 2926, 2850, (-C-H, aliphatic), 1730, 1260 (ester group), $1720 \quad(>\mathrm{C}=\mathrm{O}$ group), 1559.3 (-C=C-, aromatic), $1053.1,1255$ (ether group), 846.7 (p- sub. benzene ring), $1600,1490,1450$ (Aromatic ring).

For Decyloxy homologue

Ethylenes: (vmax/cm-1): 2920, 2832, 1437.1, (-C-H, aliphatic), 1734, 1264.4 (ester group), 1728 ( $>\mathrm{C}=\mathrm{O}$ group), 1556.3 (-C=C-, aromatic), 1053.4,1250 (ether group), 846.7 (p- sub. benzene ring), 1620,1486, 1452 (Aromatic ring)

\section{Textures by miscibility method}

$\mathbf{C}_{4}$----------- threaded nematic

$\mathrm{C}_{8}$--------------threaded nematic

$\mathrm{C}_{16------------}$ schlieren nematic

Table-2: Transition Temperatures in ${ }^{\circ} \mathrm{C}$

\begin{tabular}{|c|c|c|c|c|}
\hline Compound No & $\begin{array}{c}\text { n-alkyl }\left(\mathrm{C}_{\mathrm{n}} \mathrm{H}_{2 \mathrm{n}+1}\right) \\
\text { group }\end{array}$ & Smectic & Nematic & Isotropic \\
\hline 1 & $\mathrm{C}_{1}$ & - & - & 119.0 \\
\hline 2 & $\mathrm{C}_{2}$ & - & 86.0 & 126.0 \\
\hline 3 & $\mathrm{C}_{3}$ & - & 61.0 & 105.0 \\
\hline 4 & $\mathrm{C}_{4}$ & - & 98.0 & 123.0 \\
\hline 5 & $\mathrm{C}_{5}$ & - & 104.0 & 113.0 \\
\hline 6 & $\mathrm{C}_{6}$ & - & 105.0 & 130.0 \\
\hline 7 & $\mathrm{C}_{8}$ & - & 109.0 & 114.0 \\
\hline 8 & $\mathrm{C}_{10}$ & - & 85.0 & 125.0 \\
\hline 9 & $\mathrm{C}_{12}$ & - & 62.0 & 73.0 \\
\hline 10 & $\mathrm{C}_{14}$ & $\mathrm{C}_{16}$ & - & 15.0 \\
\hline
\end{tabular}




\section{RESULTS AND DISCUSSION:}

Novel chalconyl ester derivatives are synthesized by the condensation of dimeric trans n-alkoxy cinnamic acids and $\alpha$-4-Hydroxy benzoyl $\beta-4$ '-n-octyloxy phenyl ethylene of whose transition temperatures are lower as compared to the transition temperatures of the corresponding n-alkoxy cinnamic acids. All the members of a novel series except $C_{1}$ and $C_{2}$ are nematogenic without exhibition of smectic property. The transition temperatures as determined (table-2) from an optical polarizing microscopy (POM) are plotted versus the number of carbon atoms present in n-alkyl chain (R) of left terminal -OR. The Transition curves Cr-I/N and N-I are obtained by linking like or related points which shows phase behaviours of series as depicted in a phase diagram as shown in figure-1. Cr-N/I transition curve adopted a zigzag path of rising and falling with overall descending tendency. Cr-N/I transition curve rises and falls as light wave or appears like a serpant, instead of normal descending behaviour. The deviation from normal descending behaviours commences from an unique $\mathrm{C}_{8}$ homologue $\left[\mathrm{R}=\mathrm{R}^{\prime}\right.$ i.e. $\mathrm{H}_{17} \mathrm{C}_{8} \mathrm{O}-=-\mathrm{OC}_{8} \mathrm{H}_{17}$ end group ] and it passes through $\mathrm{C}_{10}, \mathrm{C}_{12}$, $\mathrm{C}_{14}$ and $\mathrm{C}_{16}$ homologues in more or less or negligible proportions; as shown by dotted lines in N-I transition curve showing expected descending tendency. N-I transition curve is extrapolated in left to the $\mathrm{C}_{1}$ and $\mathrm{C}_{2}$ nonmesogenic homologues to predict their hypothetically latent transition temperatures (LTT) and to highlight the appearance of odd-even effect of N-I transition curve. Oddeven effect disappears from and beyond $\mathrm{C}_{8}$ homologue where the N-I curves for odd and even homologues prior to $\mathrm{C}_{8}$ are merging into each other and then a single transition curve (N-I) is prolonged for higher homologues of longer n-alkyl chain. The LC properties vary from homologue to homologue in the same present series with changing number of carbon atoms in n-alkyl chain ' $R$ ' of $-\mathrm{OR}$; keeping $-\mathrm{OC}_{8} \mathrm{H}_{17}$ tail end unchanged throughout the series under discussion.

The lowering of transition temperatures of novel homologues as compared to corresponding dimeric trans-n-alkoxy cinnamic acids is attributed to breaking of hydrogen bonding by esterification process. Odd-even effect observed for N-I transition curve is due to sequentially added methylene unit in n-alkyl chain ' $R$ ' of -OR. The exhibition of nematogenic character from $\mathrm{C}_{3}$ to $\mathrm{C}_{16}$ homologues is attributed to the suitable magnitudes of anisotropic forces of end to end dispersion forces, dipole-dipole interactions and permanent dipolemoment across the long molecular axis as a consequence of favourable molecular rigidity and flexibility as depended on molecular structure; which facilitated the molecules of homologues $\left(C_{3}\right.$ to $\left.C_{16}\right)$ to float on the surface with statistically parallel orientational order to cause nematic mesophase formation. Inexhibition of smectogenic mesophase formation is attributed to the absence of lamellar packing of molecules in the preoccupied crystal lattices which eliminates the possibility of facilitating sliding layered molecular arrangement in floating condition for all of the homologues of a novel series. The nonmesomorphic behaviour of $\mathrm{C}_{1}$ and $\mathrm{C}_{2}$ homologue is attributed to their high crystallising tendency which arises from low magnitudes of intermolecular end to end or lateral dispersion forces and low dipole-dipole interactions, which disallows the formation of LC state and encourage high crystallising tendency. All the homologues of present series transforms into isotropic state at their isotropic temperature and then from and beyond isotropic temperature, the molecules are randomly oriented in all possible directions with high order of disorder or randomness or high entropy $(\Delta \mathrm{S}=\Delta \mathrm{H} / \mathrm{T})$ in uncontrolled manner. But on cooling the same carefully, the nematic mesophase reappeared from and below isotropic temperature at which nematic phase was appeared on heating in reversible manner. However none of the nematogenic homologues have showed smectic phase or nonmesomorphic homologues $\mathrm{C}_{1}$ and $\mathrm{C}_{2}$ showed nematic mesophase (LC) in irreversible manner in monotropic condition. The extrapolated L.T.T values [28, 29, 30, 31] from N-I transition curve for $\mathrm{C}_{1}$ and $\mathrm{C}_{2}$ are $89.0{ }^{0} \mathrm{C}$ and $86.0{ }^{0} \mathrm{C}$ respectively, but, these values are far below the isotropic temperatures of corresponding homologues $\mathrm{C}_{1}$ and $\mathrm{C}_{2}$. Therefore, before they show mesophase formation at LTT, the isotropic mass undergoes to crystallisation and hence solidifies. The changing trend in LC behaviours and properties from homologue to homologue in the same series is attributed to the progressively and sequentially added methylene unit or units at the left n-alkoxy OR group. The disappearance of odd-even effect from and beyond merging of N-I transition curves 
for odd and even initial homologues, is attributed to the longer n-alkyl chain ' $R$ ' which may coil or bend or flex or couple to lie with the principal axis of the core structure. The observed deviations from and beyond $\mathrm{C}_{8}$ unique homologue is attributed to the uncertainity in the status of n-alkyl chain ' $\mathrm{R}$ ' of -OR and tail end group $-\mathrm{OC}_{8} \mathrm{H}_{17}$ or $-\mathrm{OC}_{14} \mathrm{H}_{29}$, which affects the suitable magnitudes of molecular rigidity and flexibility as depended on unusual status of molecular structure, under the influence of exposed thermal vibrations. Some LC properties of presently investigated novel series1 are compared with the structurally similar analogous series X[32] and Y[33] as mentioned below in figure-2.

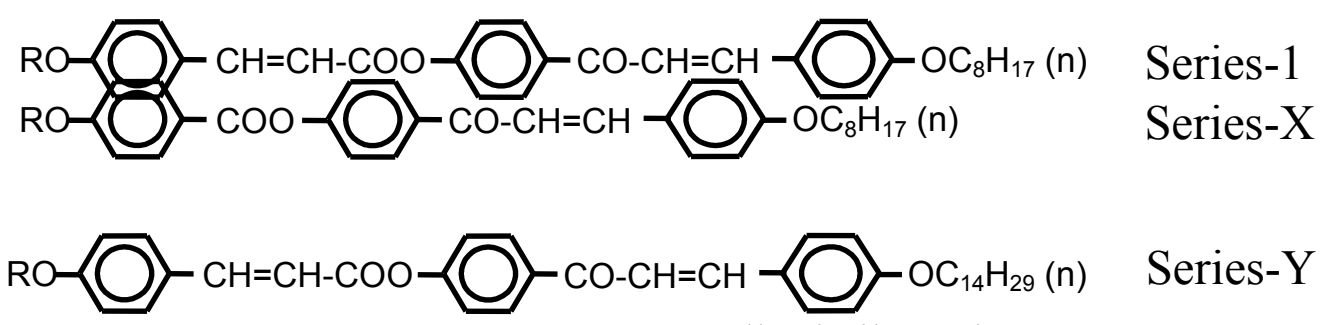

Figure-2: Structurally similar series.

Homologous series $1, \mathrm{X}$ and $\mathrm{Y}$ are identical with respect to three phenyl rings, a central bridge $-\mathrm{CO}-\mathrm{CH}=\mathrm{CH}$ - linking middle and third tail phenyl ring and left $\mathrm{n}$-alkoxy group $-\mathrm{OR}$ for the same homologue from series to series. But they differ with respect to a central bridge linking first and middle phenyl rings in case of series 1 and $\mathrm{X}$, as well as tail end groups $-\mathrm{OC}_{8} \mathrm{C}_{17}$ and $-\mathrm{OC}_{14} \mathrm{H}_{29}$ in case of series $1, \mathrm{X}$, and $\mathrm{Y}$. Thus, combined effect of molecular rigidity and flexibility creates differing features, which causes variations in LC properties and the degree of mesomorphism among the series $1, \mathrm{X}$ and $\mathrm{Y}$ under and, among the homologues of same series. Following table-3 represents some relative thermometric properties for the series under comparison.

Table-3: Relative thermal stabilities in ${ }^{0} \mathrm{C}$

\begin{tabular}{|c|c|c|c|}
\hline Series & Series-1 & Series-2 & Series-3 \\
\hline $\begin{array}{c}\text { Sm-I or Sm-N } \\
\begin{array}{c}\text { Commencement of smectic } \\
\text { phase }\end{array}\end{array}$ & - & - & - \\
\hline N-I & 112.66 & 98.88 & 99.75 \\
$\begin{array}{c}\text { Commencement of nematic } \\
\text { phase }\end{array}$ & {$\left[\mathrm{C}_{3}-\mathrm{C}_{16}\right]$} & $\left.\mathrm{C}_{6}-\mathrm{C}_{18}\right]$ & $\mathrm{C}_{6}$ \\
\hline $\begin{array}{c}\text { Total } \\
\text { mesophaselength }[\mathrm{Sm}+\mathrm{N}] \\
\text { in }{ }^{0} \mathrm{C}\end{array}$ & 05.0 to 44.0 & 12.0 to 37.0 & 19.0 to 34.0 \\
\hline $\mathrm{C}_{3}$ & $\mathrm{C}_{4}$ & $\mathrm{C}_{14} \quad \mathrm{C}_{8}$ & $\mathrm{C}_{6} \quad \mathrm{C}_{8}$ \\
\hline
\end{tabular}

Table-3 clearly indicates that,

- All the homologous series $1, \mathrm{X}$ and $\mathrm{Y}$ under comparison are only nematogenic without exhibition of smectogenic property.

- Nematogenic mesomorphism commences identically from $\mathrm{C}_{3}$ homologue of the series-1 and $\mathrm{X}$, but it commences late from $\mathrm{C}_{6}$ homologue of a series-Y.

- Thermal stability for the series $X$ and $Y$ under comparison are almost nearer (98.88 99.75) or equivalent whereas it is higher (112.66) for a present series-1.

- The lower mesophaselenths (nematic) are in increasing order whereas, upper mesophaselenths are in the decreasing order of magnitudes, from series 1 to series-X to series-Y. 
- Mesomorphic - isotropic transition curves of series $1, \mathrm{X}$, and $\mathrm{Y}$ in their respective phase diagrams exhibited odd-even effect with more or less or negligible deviation from its expected descending tendency.

The exhibition of only nematic property by the series $1, \mathrm{X}$ and $\mathrm{Y}$ is attributed to their identical geometric shapes, aromaticity including one or both central bridges, tail end groups except $-\mathrm{OC}_{14} \mathrm{H}_{29}$, etc. which causes the end to end and lateral intermolecular dispersion forces of suitable and of different magnitudes which resists exposed thermal vibrations to induce nematic mesophase formation for different range of temperatures. However the magnitudes of intermolecular dispersion forces of cohesion and closeness are incapable of inducing lamellar packings of molecules in the crystal lattices of homologues, belonging to series $1, \mathrm{X}$ and $\mathrm{Y}$ which eliminates the possibilities of sliding layered molecular arrangement in floating condition and avoids the facilitating possibility of smectogenic mesophase formation. Early commencement from $\mathrm{C}_{3}$ homologue for series 1 and $\mathrm{X}$ is attributed to the equivalent extent of molecular noncoplanarity irrespective of changing a central bridge $-\mathrm{COO}$ - or $-\mathrm{CH}=\mathrm{CH}-\mathrm{COO}$ - linking first and middle phenyl ring and a commonly present tail end group $-\mathrm{OC}_{8} \mathrm{H}_{17}$ and second central bridge $-\mathrm{CO}-\mathrm{CH}=\mathrm{CH}$ - linking middle and third phenyl ring. Thus, presence of same tail ends and same chalconyl second central bridge containing multiple double bond reduces effect on the extent of molecular noncoplanarity irrespective of - COO- or $\mathrm{CO}-\mathrm{CH}=\mathrm{CH}$ - first central bridge. However on changing tail end group from $-\mathrm{OC}_{8} \mathrm{H}_{17}$ to $-\mathrm{C}_{14} \mathrm{H}_{29}$, the extent of molecular noncoplanarity vary to such an extent in case of series-Y that, the commencement of nematic phase takes place later from $\mathrm{C}_{6}$ homologue. However thermal stabilities for nematic adopted decreasing order from series- 1 to almost equivalent thermally stable series-X and $\mathrm{Y}$; because, the energy stored by the molecules $(\Delta \mathrm{H})$ at constant pressure is relatively higher for presently investigated series-1, which resisted exposed thermal vibrations with wider range of temperature. Hence, relative enthalpy value $(\Delta \mathrm{H})$ or the energy stored in the homologue molecules of series-1 raises transition temperatures and thermal resistivity, resulting into highering of thermal stability and the upper mesophaselength as compared to series-X and Y. Deviations observed in mesomorphic - Isotopic transition curves, instead of their adoption of normal descending behaviours, is attributed to the unusual status of n-alkyl chain on both terminal end groups.

\section{Conclusions:}

- Chalconyl ester novel homologous series of present investigation is enantiotropically nematogenic with absence of smectic property, whose thermal stability is 112.66 and considerable degree of mesomorphism with its middle ordered melting type and exhibited more or less or negligible deviation in N-I transition curve.

- The group efficiency order derived for nematic on the basis of (a) thermal stability (b) early commencement of nematic phase and (c) upper and lower degree of mesomorphism is as under.

(a) Nematic:

$$
\text { Series-1 }>\text { Series- } \mathrm{X} \sim \text { Series-Y }
$$

(b) Nematic:

(c) Nematic:

$$
\text { Series- } 1=\text { Series- } \mathrm{X}>\text { Series- } \mathrm{Y}
$$

\begin{tabular}{|c|c|}
\hline $\begin{array}{l}\text { Lower Degree of } \\
\text { mesomorphism }\end{array}$ & Series-Y $>$ Series- $\mathrm{X}>$ Series \\
\hline $\begin{array}{l}\text { Upper Degree of } \\
\text { mesomorphism }\end{array}$ & ries- $\searrow$ \\
\hline
\end{tabular}

- Chalconyl LC derivatives may be useful for the study of binary system for LC Devices to be operated at desired temperature. 
- Chalconyl derivatives being bioactive molecules can be studied as anticancer, antimalarial, antibacterial etc.

- Mesomorphism is very sensitive and susceptible to molecular structure as a consequence of molecular rigidity and flexibility.

- Present investigation supports and raises the credibility to conclusions drawn earlier.
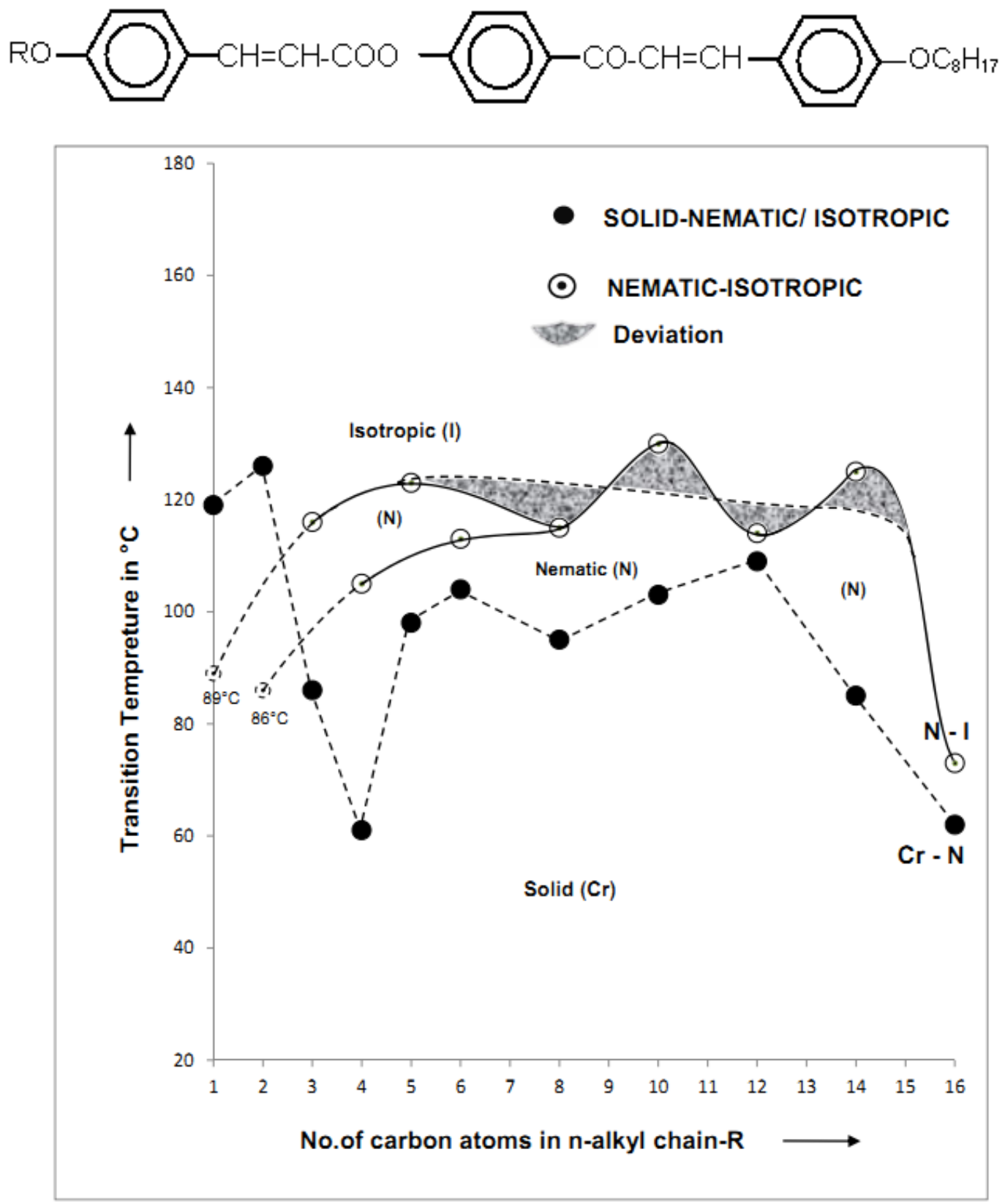

\section{Acknowledgement:}

Authors acknowledge thanks to the Dr. N.N.Vyas, the head of chemistry department and the principal Dr. M.B.Patel of the college for their supportive view and providing research facility of present investigation. Authors are also thankful to Dr. A.V.Doshi, Ex. Principal, M.V.M. Science and Home. Sc. College, Rajkot for his valuable co operation and support as and when needed throughout this present investigation. Authors acknowledge thanks to dept. of chemistry, S. P. University, Vidhyanagar for analytical and spectral services. 


\section{References:}

[1] F. Reinitzer, Monatsh 9, 421 (1888)

[2] DR. L.K.Omray, current trends in Technology and science ISSN: 2279-0535, vol. II, Issue: VI, "Liquid Crystals as novel vesicular delivery system:" A review.

[3] S. Narmura. Advance LCD technologies, Displays 22 (1) (2001) PP. 1

[4] W. S. Kim, S.J. Elston and F.P. Raynes, Displays 29 (2008). PP. 458-463

[5] Imaran Tadwee, Dr. Sahanashahi, Vivek Ramteke, Iftequar Syed, Liquid Crystals pharmaceutical Application: A review, IJPRAS, ISSN 2277-36. Vol. 1, Issue (2012), 06-11.

[6] G.w. Gray and P.A. Winsor (Eds) Liquid Crystals and plastic crystals, chapter-6.2, The role of liquid crystal in life processes by G.T. Stewart, Vol-1, PP. 308-326.

[7] C.A. Calliste, J.C. Le Bail, P. Trouilas, C Poug, A.j. Chulia, L.J. Doroux, AnticancerRes. 2001, 21, 3949-3956.

[8] P.J. Collings and M. Hird (1997), Introduction of Liquid Crystals chemistry and physics, Taylor and Francis Ltd. U.K. 1998.

[9] C. T. Imrie, Crystal dimers. Struct. Bond 95 (1999) PP. 149-192.

[10] G. W. Gray (1974) In; G.W. Gray and P.A. Winsor (eds) liquid crystals and plastic crystals, Chapter-4, Volume-1, PP-103-153.

[11] G.W. Gray, Molecular structures and properties of liquid crystals, Academic press, Landon, 1962.

[12] G.W. Gray and B. Jones, Mesomorphism and chemical constitution part-3, The effect of halogen substitution on the 4-alkoxy benzoic acids. Journal of chemical society (1954), PP. 25562562.

[13] P.A. Henderson, O. Neimeyer, and C.T. Imrie, Methylene linked liquid crystal dimer, Liq. Cryst.28 (2001), PP. 463-472.

[14] Hird. M, Toyne. K. J. and Gray. G. W, Day S.E and Mc. Donell D.G (1993), Liq. Cryst. 15, PP. 123.

[15] Marcos. M, Omenat. A, Serrano. J.L and Ezcurra.A (1992), Adv. Matter, 4, 285.

[16] Hird. M,Toyne. K.J, Gray G. W., Day S.E. (1993) Liq. Cryst. 14, PP. 741.

[17] C.T Imrie and G.R, Luckhrust,"Liquid Dimers and oligomers in handbook of Liquid crystal, Law molecular liquid crystals;" Vol. 2B , D. Demus, J.W. Goodby, G.W. Graw, H. Spiess and V. Vill eds, Willey- VCH weinhe 1998, pp-801-833.

[18] D. Demus, Plenary lectures 100 years of liquid crystals chemistry, Thermotropic liquid crystals with conventional molecular structures, Liq.Cryst, 5 (1988). PP. 75-110.

[19] D. Demus, 100 years of liquid crystal chemistry, mol.cryst. liq.cryst. 165 (1988) PP. 45-84.

[20] Doshi et al (1) D.M. Suthar and A.V. Doshi, Mol. Cryst. Liq. Cryst. Vol. 575, PP. 76-83. (2) H. N. Chauhan and A.V. Doshi, Mol. Cryst. Liq. Cryst. Vol. 570, PP. 92-100 (2013). (3) R.P. Chaudhari, M.L. Chauhan and A.V. Doshi, Vol. 575, PP. 88-95 (2013). (4) U.C. Bhoya, N.N. Vyas and A.V. Doshi, Mol. Cryst. Liq. Cryst. Vol. 552. PP. 104-110 (2012).

[21] D.M. Suthar, A.A. Doshi and A.V.Doshi Synthesis and evaluation of novel Liquid Crystalline Homologous Series $\alpha-4-(4 '-n-a l k o x y$ Cinnamoyloxy) benzoyl- $\beta-3$ ', 4', Dimethoxy Phenyl Ethylenes". Mole. Cryst. Liq. Cryst. Vol. 527, PP. 51-58, (2013). 
[22] Patel B. H. \& Doshi A.V. "Mesomorphism and Molecular Structure Novel Homologous Series -4-(4'-n-alkoxy Cinnamoyloxy)-4' 'methoxy Benzyl Benzoates". Mol. Cryst. Liq. Cryst., Vol-607, PP. 78-86 (2015).

[23] Patel B.H., V.R.Patel \& Doshi A. V. "Mesomorphism Dependence on Molecular Flexibility by $-\mathrm{OCH}_{3}$ And -H Terminal Units” Mol. Cryst. Liq. Cryst., Vol-609, PP. 10-18 (2015).

[24] Rajesh B. Marathe, N.N. Vyas and Doshi A. V. " Molecular Flexibility Operated Mesomorphism” ILCPA, Scipress Ltd, Vol-52, PP. 163-171, (2015).

[25 ] A. Hildesheimer, Monatsh. Chem., 22, 487 (1901).

[26] N.G. Nagaveni and Prasad, V. Phase Tran., 86, 12, 1227, 2013.

[27] Uhood J. A., international journal of Molecular Science., Vol.12; PP. 3182- 3190(2011)

[28] J. M. Lohar and A. V. Doshi, "Studies on mixed mesomorphism: Determination of Latent Transition Temperature (LTT) by extrapolation" proceeding of Indian Acad. Of ScienceBangalore, Vol-105, No-3, June 1993, PP. 209-214.

[29] K. J. Ganatra and A. V. Doshi, "Study of Binary systems inducing mesophase and determination of Latent Transition Temperature", Journal of Indian Chem. Soc., Vol. 77, July-2000, PP.209-214.

[30] U.C. Bhoya, N.N. Vyas and A. V. Doshi, "Determination of Latent mesogenic Behaviour in Non-mesogenic compounds by extrapolation.” Mol. Cryst. Liq. Cryst. Liq. Cryst. Vol. 552, PP-104$110,2012$.

[31] A. V. Doshi, U. C. Bhoya and J. J. Travadi, "Determination of Transition Temperatures of Non-Mesogenic by extrapolation method in Binary Systems," Mol. Cyst. Liq. Cryst. Vol. 552, PP. 10-15, 2012.

[32] Pandya S.H. and V.R.Patel manuscript of the research paper. Entitled "Study of Deviation from Normal Liquid Crystal Behaviour of Mesomorphic-Isotropic transition Curve in a Chalconyl Ester Series with Equipolar Terminal End Groups" submitted for publication Mol. Liq. Cryst. Journal on $12^{\text {th }}$ September 2015.

[33] B.B.Jain \& R.B.Patel "Study of Molecular Flexibility Operated Mesomorphism" International Letters of Chemistry, Physics and Astronomy Vol. 58(2015) pp 16-25. 